\title{
Cue-Evoked Dopamine Release Rapidly Modulates D2 Neurons in the Nucleus Accumbens During Motivated Behavior
}

\author{
Catarina Owesson-White, ${ }^{1}$ Anna M. Belle, ${ }^{1}$ Natalie R. Herr, ${ }^{1}$ Jessica L. Peele, ${ }^{1}$ Preethi Gowrishankar, ${ }^{1}$ \\ Regina M. Carelli, ${ }^{2,3}$ and $\odot$ R. Mark Wightman ${ }^{1,3}$ \\ ${ }^{1}$ Department of Chemistry, ${ }^{2}$ Department of Psychology and Neuroscience, and ${ }^{3}$ Neuroscience Center, University of North Carolina at Chapel Hill, Chapel \\ Hill, North Carolina 27599
}

\begin{abstract}
Dopaminergic neurons that project from the ventral tegmental area (VTA) to the nucleus accumbens (NAc) fire in response to unpredicted rewards or to cues that predict reward delivery. Although it is well established that reward-related events elicit dopamine release in the NAc, the role of rapid dopamine signaling in modulating NAc neurons that respond to these events remains unclear. Here, we examined dopamine's actions in the NAc in the rat brain during an intracranial self-stimulation task in which a cue predicted lever availability for electrical stimulation of the VTA. To distinguish actions of dopamine at select receptors on NAc neurons during the task, we used a multimodal sensor that probes three aspects of neuronal communication simultaneously: neurotransmitter release, cell firing, and identification of dopamine receptor type. Consistent with prior studies, we first show dopamine release events in the NAc both at cue presentation and after lever press (LP). Distinct populations of NAc neurons encode these behavioral events at these same locations selectively. Using our multimodal sensor, we found that dopamine-mediated responses after the cue involve exclusively a subset of D2-like receptors (D2Rs), whereas dopamine-mediated responses proximal to the LP are mediated by both D1-like receptors (D1R) and D2Rs. These results demonstrate for the first time that dopamine-mediated responses after cues that predict reward availability are specifically linked to its actions at a subset of neurons in the NAc containing D2Rs.
\end{abstract}

Key words: dopamine; dopamine receptors; electrophysiology; iontophoresis; reward anticipation; voltammetry

Significance Statement

Successful reward procurement typically involves the completion of a goal-directed behavior in response to appropriate environmental cues. Although numerous studies link the mesolimbic dopamine system with these processes, how dopamine's effects are mediated on the receptor level within a key neural substrate, the nucleus accumbens, remains elusive. Here, we used a unique multimodal sensor that reveals three aspects of neuronal interactions: neurotransmitter release, cell firing, and dopamine-receptor type. We identified a key role of D2-like receptor (D2R)-expressing neurons in response to a reward-predicting cue, whereas both the D2R and D1R types modulate responses of neurons proximal to the goal-directed action. This work provides novel insight into the unique role of D2R-mediated neuronal activity to reward-associated cues, a fundamental aspect of motivated behaviors.

\section{Introduction}

The nucleus accumbens (NAc), which receives glutamatergic inputs from the prefrontal cortex, basolateral amygdala, and hip-

\footnotetext{
Received Feb. 4, 2016; revised March 23, 2016; accepted April 20, 2016.

Author contributions: C.A.O.-W., R.M.C., and R.M.W. designed research; C.A.O.-W., A.M.B., N.R.H., J.L.P., and P.G. performed research; C.A.O.-W. analyzed data; C.A.O.-W., R.M.C., and R.M.W. wrote the paper.

This work was supported by the National Institutes of Health (Grant DA010900 to R.M.W. and Grant DA017318 to R.M.C.). We thank the Carolina Chemistry Electronics Facility for fabricating the instrumentation for this project and Elyse Dankoski for helping with manuscript preparation.

The authors declare no competing financial interests.

Correspondence should be addressed to R. Mark Wightman, PhD, Department of Chemistry, Venable Hall, CB

\#3290, University of North Carolina at Chapel Hill, Chapel Hill, NC 27599-3290. E-mail: rmw@unc.edu.
}

pocampus, has long been recognized as a critical structure underlying reward seeking (Wise, 2004; Koob and Volkow, 2010; Britt et al., 2012; Trifilieff et al., 2013). Dopamine release appears to be essential to hedonic processing, but also occurs during learning about reward. Indeed, animals will self-administer dopaminergic agonists directly into the NAc (Ikemoto, 2007) and studies support a key role of dopamine in learning and decision making (Schultz, 2007; Schultz et al., 2015). Although numerous studies have linked dopamine release to behavioral events, defin- 
ing its specific roles has proven difficult (Kiyatkin and Rebec, 1999; Belle et al., 2013). This is because it acts as a neuromodulator, modifying excitatory inputs into the NAc rather than driving activity directly. Resolving the multifaceted roles of dopamine in the minute volume of the extracellular space requires studies on a microscopic scale; that is, at the neuronal and synaptic level.

The primary output neurons of the NAc are GABAergic medium spiny neurons (MSNs), which comprise $95 \%$ of the neurons in this region (Gerfen and Surmeier, 2011). Excitatory and inhibitory inputs to these MSNs are modulated by two pharmacologically distinct classes of dopamine receptors, D1-like receptors (D1Rs) and D2-like receptors (D2Rs), which have different roles in different brain regions (Tritsch and Sabatini, 2012). MSNs in the NAc contain either D1Rs or D2Rs, but few contain both (Valjent et al., 2009). Studies using systemic injections or microinfusions in intact animals suggest that dopamine exerts specific behavioral effects via different receptors (du Hoffmann and Nicola, 2014). For example, microinfusions of dopamine antagonists into the NAc suppress operant responding for optical activation of dopamine neurons expressing channelrhodopsin (Steinberg et al., 2014). However, such studies are often confounded because pharmacological manipulations that affect the whole brain or even an entire subregion can alter behavior. Optogenetic activation of D1- or D2-containing MSNs has implicated rewarding and aversive roles for those neurons, respectively (Kravitz et al., 2012). In contrast, in the striatum, cue presentation activated both receptors nearly simultaneously in mice expressing a fluorescent calcium marker that distinguished D1R and D2Rs on MSNs (Cui et al., 2013). Therefore, although advances have been made, the limited temporal and spatial resolution has impeded assignment of specific roles for these receptors in the NAc during reward seeking.

We have developed a sensor that characterizes the functions of D1Rs and D2Rs in the NAc during behavior without requiring genetic manipulation. Our sensor probes presynaptic dopamine release and its effects on postsynaptic neurons concurrently by combining electrochemistry and single-unit recording (Takmakov et al., 2011). Prior voltammetric studies have revealed that cues predicting reward elicit dopamine release in the NAc of trained animals (Phillips et al., 2003; Cheer et al., 2007) and electrophysiological studies show that this arises due to increased firing of VTA dopamine neurons (Schultz et al., 1997; Schultz, 2007). Using this multimodal sensor, we have shown that dopamine release during goal-directed actions for food reward (Cacciapaglia et al., 2011) and cocaine self-administration (OwessonWhite et al., 2009) is accompanied by firing rate changes in unique subsets of MSNs in the NAc. Here, we added iontophoretic barrels to the sensor, which enables determination of receptor type by detecting changes in firing rate after delivery of subtype-selective dopaminergic antagonists and agonists. We term this method "controlled" iontophoresis because the ejections contain an electroactive marker, enabling reproducible and quantitative drug delivery (Belle et al., 2013). To determine whether discrete reward-related events could be linked to specific subpopulations of NAc neurons, we probed the core and shell of the NAc, two functionally distinct subregions (Zahm and Heimer, 1990; Kupchik et al., 2015), in rats performing intracranial self-stimulation (ICSS) (Wise, 2004; Owesson-White et al., 2008). The nanometer spatial resolution and subsecond temporal resolution enabled, for the first time, measurements that link dopamine release related to discrete task events (cue vs lever press, LP) to distinct interactions at D1R- and D2R-containing MSNs.

\section{Materials and Methods}

Animals. Male Sprague Dawley rats $(N=41$ total) weighing 250-350 g (Charles River Laboratories) were housed in pairs initially and then individually after surgery. They were kept on a 12:12 light/dark cycle (lights on at 6:00 A.M.) with experiments conducted between 8:00 A.M. and 8:00 P.M. The animals were given food and water ad libitum. The procedures were approved by the University of North Carolina at Chapel Hill Institutional Animal Care and Use Committee. We use upper case $N$ to refer to number of animals and lower case $n$ to refer to number of locations.

Drugs and reagents. Dopamine receptor antagonists and antagonists were purchased from Sigma-Aldrich, dissolved in $\mathrm{NaCl}$ containing acetaminophen (ACP), all at $5 \mathrm{~mm}$, and delivered via iontophoretic barrels. ACP served as the electroactive marker for controlled iontophoresis (Belle et al., 2013).

Surgical procedures. Rats were anesthetized with isoflurane (induction 4\%; surgical maintenance 1.5-2.0\%) and secured in a stereotaxic frame (Kopf Instruments). A guide cannula (Bioanalytical Systems) for the multimodal sensor was positioned $2.5 \mathrm{~mm}$ deep into the brain above the NAc (core:+1.3 AP, 1.3 ML, shell: +1.7 AP, 0.8 ML from bregma, all coordinates from Paxinos and Watson, 2007). A reference electrode (Ag/ $\mathrm{AgCl}$ ) was placed in the contralateral hemisphere and a bipolar stimulating electrode (Plastics One) was positioned in the ipsilateral VTA $(-5.2$ $\mathrm{AP}, 1.0 \mathrm{ML}$ from bregma and $7.8 \mathrm{~mm}$ below dura). The electrodes and guide cannula were affixed to the skull with stainless-steel screws and dental cement (Lang Dental). Postoperatively, rats received 100\% oxygen for a few minutes and ACP orally $(15 \mathrm{mg} / \mathrm{kg})$ to aid recovery. All animals recovered for at least $2 \mathrm{~d}$ before training.

ICSS training. Rats were trained for $3 \mathrm{~d}$. Initially, the lever was continuously presented and each LP (LP) delivered the electrical stimulation $\sim 200$ ms later (24 biphasic pulses, $60 \mathrm{~Hz}, 125-150 \mu \mathrm{A}, 2$ ms per phase). Next, rats were trained to LP on a variable-time out (VTO) schedule, fixed-ratio 1, similar to previous studies (Owesson-White et al., 2008). Here, for trials $1-50$, an audiovisual cue (a $67-\mathrm{dB}, 1 \mathrm{kHz}$ paired with cue-light on) was presented with the lever, with a 9-16 s intertrial interval (ITI). During the ITI, the cue light was off and the house light was on. In subsequent training trials (51-200), the cue preceded the lever by $2 \mathrm{~s}$. The rats were then trained for 30 trials on a longer ITI, $18-27 \mathrm{~s}$, which was used on experimental days. The longer ITI accommodates the $15 \mathrm{~s}$ drug ejection periods. The lever was extended until LP or for a maximum of $15 \mathrm{~s}$. At each location, there was a control experiment ( 30 trials) followed by two to three drug experiments (30 trials each). Depending on how quickly the rat responded on the VTO schedule, a single experiment consisting of 30 trials lasted between 11.5 and $19 \mathrm{~min}$. For ejections from all barrels, recordings at one location consisted of 120 trials.

Electrochemistry/electrophysiology. The sensor with iontophoretic barrels and a carbon-fiber electrode was made as described previously (Belle et al., 2013). Electrochemical data, behavioral time stamps, iontophoretic ejection, and electrical stimulation were controlled with HDCV software written in LabVIEW (National Instruments; Bucher et al., 2013). Combined electrochemistry/electrophysiology recordings (Takmakov et al., 2011) were made as described previously (Owesson-White et al., 2009). Cyclic voltammetry used a triangular waveform $(-0.4 \mathrm{~V}$ to $1.3 \mathrm{~V}$ and back at $400 \mathrm{~V} / \mathrm{s}$ ) and was repeated at $0.2 \mathrm{~s}$ intervals. Single-unit activity was collected in $0.2 \mathrm{~s}$ bins.

Data acquisition. The sensor was lowered in $\sim 100 \mu \mathrm{m}$ increments for isolation of single units. When multiple units were recorded, the sensor was lowered at least $300 \mu \mathrm{m}$ to avoid recording the same MSN. The iontophoresis barrels were primed at $400 \mu \mathrm{m}$ above the NAc to find the optimal current for the desired drug concentration and to verify that ejections were consistent. The concentrations of electroinactive drugs ejected were calculated from the amplitude of the voltammetric response to ACP and the electrophoretic mobility of the drug relative to ACP (Herr et al., 2010). Ejections typically resulted in an average concentration of 2-30 $\mu \mathrm{m}$ of drug in the region sensed by the carbon fiber. Based on 
A

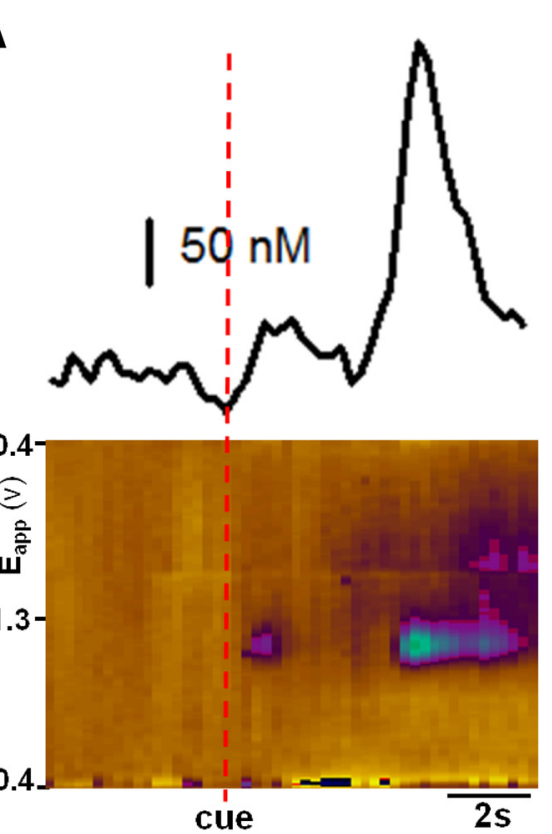

B

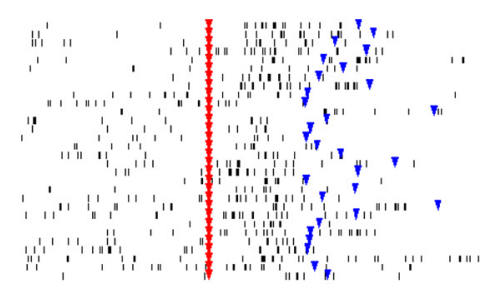

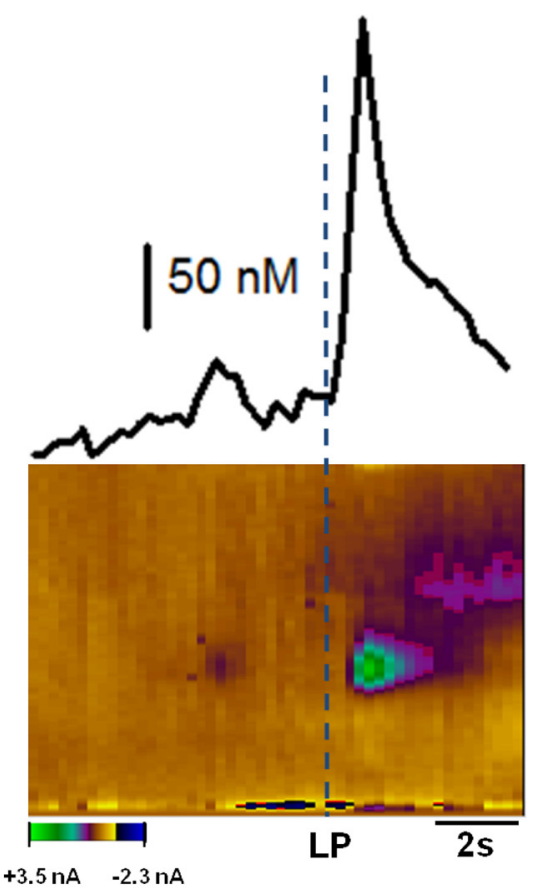

$+3.5 \mathrm{nA} \quad-2.3 \mathrm{nA}$
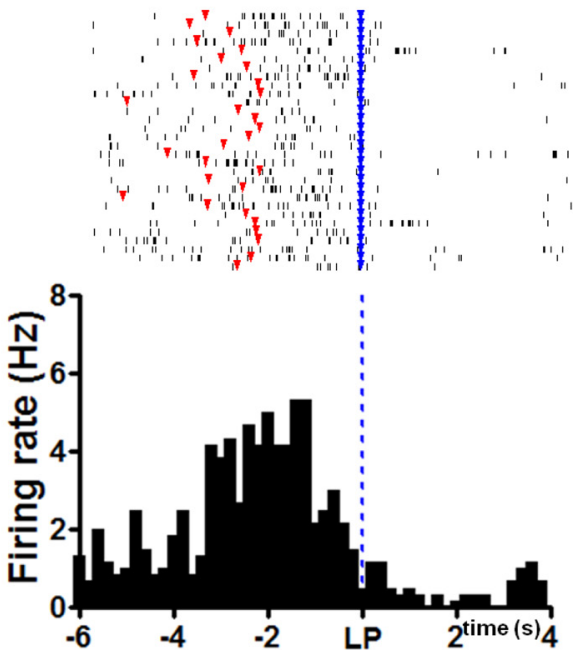

Figure 1. Dopamine response and single-unit events in the NAC during ICSS from a single anatomical location. $A$, Average dopamine concentration measured during 30 LPs in a single representative experiment. Left, Traces aligned to the cue (red line). Right, Same traces but aligned to LP (blue line). Corresponding set of cyclic voltammograms are given in the 2D color plots that show data collected for a 10 s period before and after the cue or LP. $y$-axis: applied voltage $\left(E_{\text {app }}\right)$; $x$-axis: time (s), current is shown in false color. $\boldsymbol{B}$, Raster plots of single-unit activity and histograms recorded at the same site in a single representative experiment. Left, Rasters aligned to the cue (red symbols). Right, Same traces aligned to LP (blue symbols).

our characterization of iontophoresis (Kirkpatrick et al., 2014), the amounts ejected were subnanomole.

Data analysis. Dopamine was extracted from the background-subtracted cyclic voltammograms with principal component analysis (Rodeberg et al., 2015). Neural activity was characterized with raster displays and perievent histograms across distinct time domains that bracketed the iontophoretic ejections and/or behavioral events (Cheer et al., 2005).

MSNs were classified into cue-responsive (all responses after the cue were excitatory), LP-excitatory, LP-inhibitory, or nonphasic (NP) cells using $z$-score statistics. $z$-scores were calculated as $(x+b) / s$, where $x$ is the mean firing rate during $1.4 \mathrm{~s}$ after cue onset and $0.6 \mathrm{~s}$ starting $0.2 \mathrm{~s}$ before LP, $b$ is the mean firing rate during task baseline $(2 \mathrm{~s}$ period preceding the response, for cue cells task baseline began $4 \mathrm{~s}$ before cue onset and for LP cells baseline starts $6 \mathrm{~s}$ before LP), and $s$ is the SD of task baseline. Positive $z$-scores were significant if they were greater than or equal to +1.65 , and negative $z$-scores were significant if $\leq-1.65$

(Owesson-White et al., 2009). Plots were aligned to either cue or LP to determine whether the MSNs responded to the either event. NP indicates cells that did not respond to either event.

To chemotype MSNs, baseline (BL) firing rates before iontophoretic ejections (15 s, 30 trials) were compared with firing rates during the iontophoretic ejections (15 s, 30 ejections) while the rats were executing ICSS. MSNs were classified as $\mathrm{D} 1 \mathrm{R}$ or $\mathrm{D} 2 \mathrm{R}$ if the firing rates during the time before the cue changed significantly during iontophoretic ejections of the specific antagonist compared with baseline (paired $t$ test). We also chemotyped the MSNs during the ICSS behavior. Both methods gave identical identification of the receptor subtype present.

SEMs are denoted by dashed lines or error bars in the figures. Statistical tests were performed with GraphPad software.

Histology. Electrode placement was verified after a lethal dose of sodium urethane $(2 \mathrm{~g} / \mathrm{kg}$, i.p.). A constant current of $500 \mu \mathrm{A}$ was applied twice for $10 \mathrm{~s}$ to generate an electrolytic lesion. Rats were perfused with $300 \mathrm{ml}$ of saline, followed by $300 \mathrm{ml}$ of $10 \%$ formalin solution. Brains were removed, cryoprotected, and sectioned coronally at $40 \mu \mathrm{m}$ on a cryostat. Sections were viewed with bright-field microscopy. Approximate recording sites are shown in Figure $7 C$.

\section{Results}

Reward-predicting cues trigger dopamine release in NAc shell and core Reward procurement involves waiting for a signal to engage in goal-directed behavior, and performing the behavior when that condition occurs. Importantly, these actions rarely occur in isolation, but are often embedded in sequential events. To examine this temporal sequence, we used ICSS in a paradigm that required the rat to wait for reward availability (Owesson-White et al., 2008).

We measured dopamine in the NAc by fast-scan cyclic voltammetry with a carbon-fiber microelectrode. Consistent with previous work in the NAc shell (Owesson-White et al., 2008), cue presentation evoked transient dopamine release and LP resulted in a second, larger dopamine transient arising from electrical stimulation of dopamine cell bodies. Figure 1 shows a representative example of a location with cue- and LP-evoked transients. These dopaminergic features were apparent whether the traces were aligned to the cue (Fig. 1A, left) or LP (Fig. 1A, right). Dopamine responses to the cue in the core were present after a $3 \mathrm{~d}$ training period, whereas responses to the cue appeared in the shell on the first day. Overall, dopamine responses to both the cue and electrical self-stimulation occurred in $81 \%$ of NAc locations $(N=21$ rats, averaged responses in each subregion in Fig. $2 A)$. When cue and LP-evoked dopamine release events were compared between the core and the shell, we found that LP-evoked dopamine release was significantly greater in the core. A two-way ANOVA showed a main effect of time (Fig. $2 A ; F_{(9,510)}=16.30$, 

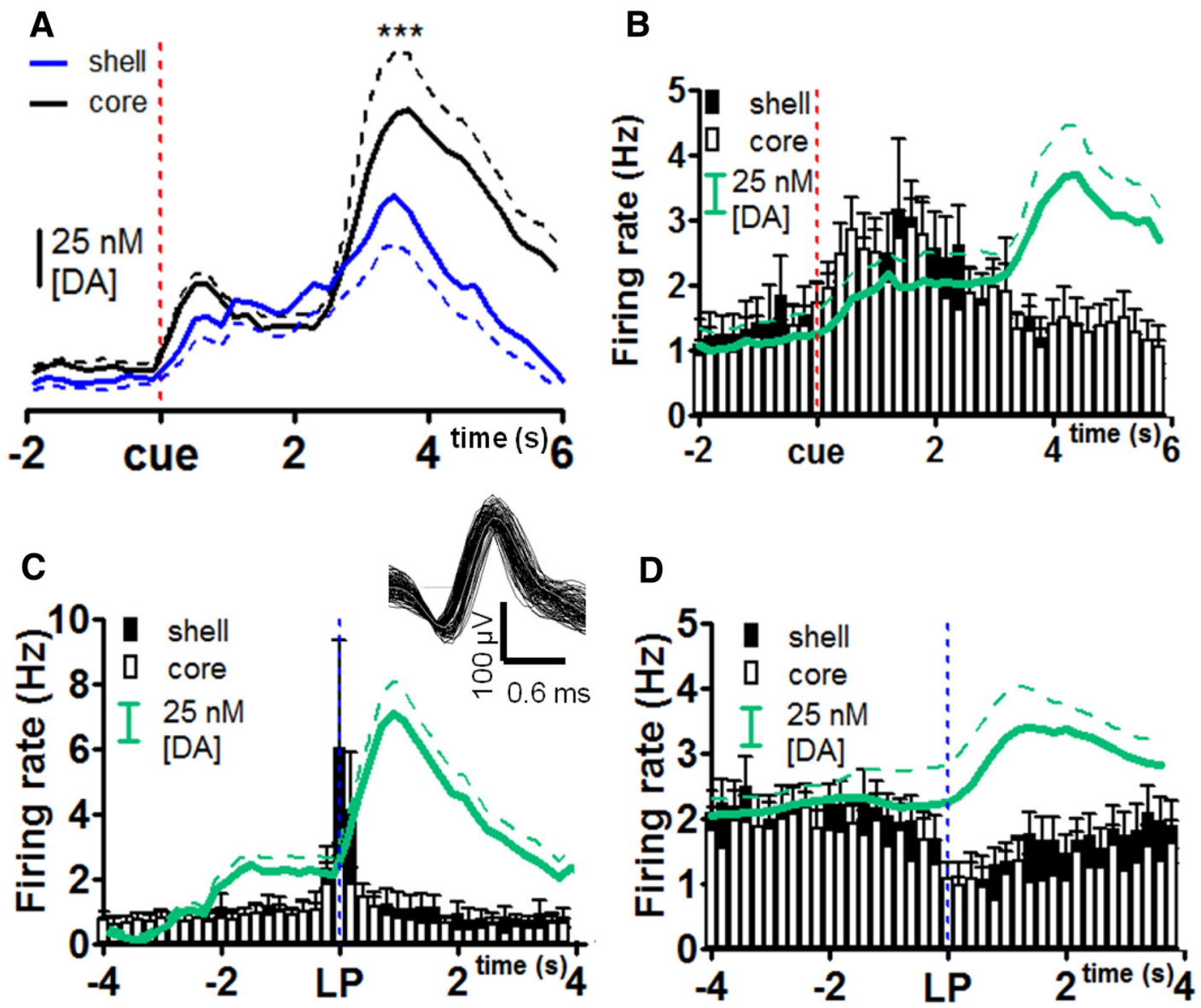

\section{E Cue-responsive}

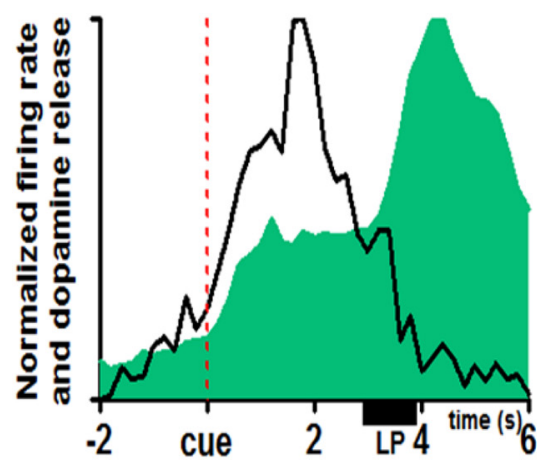

F $\underline{\text { LP-excitatory }}$

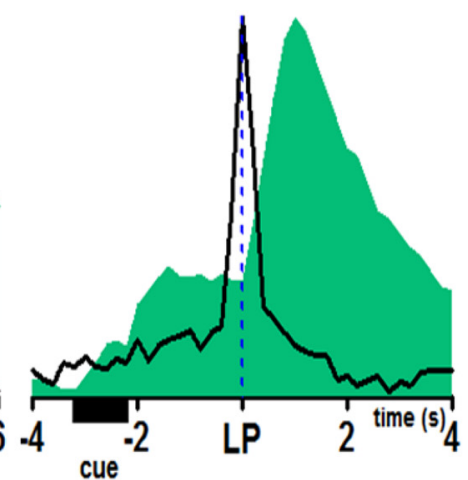

G LP-inhibitory

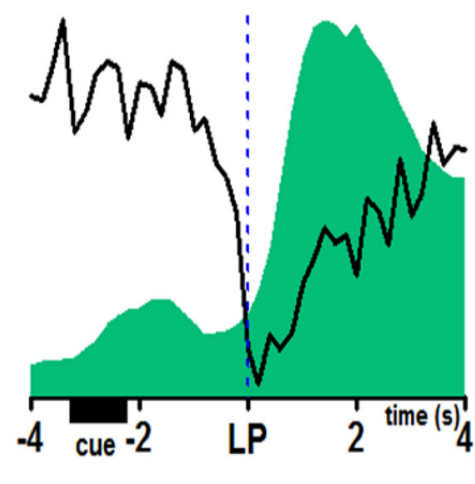

Figure 2. MSN cell-firing patterns and dopamine traces in the core and shell. $\boldsymbol{A}$, Averaged dopamine concentration responses in the shell ( $n=33$ locations) and core ( $n=20$ locations), ${ }^{* * *} p<$ 0.001. $\boldsymbol{B}$, Histograms of firing responses of cue-responsive cells in core $(n=5)$ and shell $(n=6)$. $\boldsymbol{C}$, Histograms from LP-excitatory cells sorted by region, core $(n=10)$, and shell $(n=15)$. Inset: Single MSN waveform during ICSS. $\boldsymbol{D}$, Histograms from LP-inhibitory cells in core $(n=13)$ and shell $(n=18)$. In $\boldsymbol{B}-\boldsymbol{D}$, the average dopamine concentration at the sites where the cells were recorded is shown in green. $\boldsymbol{E}-\mathbf{G}$, Timing relationship between cell-firing rate (black lines) and dopamine release (green shaded) for cue-responsive, LP-excitatory, and LP-inhibitory cell types, respectively. Responses are scaled so that they show the change from minimum to maximum for dopamine and firing rate shown in $\boldsymbol{E}$ and $\boldsymbol{F}$, whereas the opposite is true for the firing rate shown in $\boldsymbol{G}$.

$\left.{ }^{* * *} p<0.001\right)$ a main effect of subregion $\left(F_{(1,510)}=10.65,{ }^{* *} p<\right.$ $0.01)$, and a significant interaction between time and subregion $\left(F_{(9,510)}=1.927,{ }^{*} p<0.05\right.$, Bonferroni's test, $\left.{ }^{* *} p<0.001\right)$.

Changes in firing rate are time locked to behavioral events in ICSS trials

During the voltammetric recordings, we measured unit activity of cells adjacent to the carbon fiber concurrently to determine whether changes in MSN firing accompany dopamine transients. On aver- age, baseline firing rate was $\sim 1 \mathrm{~Hz}$, which is characteristic of MSNs (Gage et al., 2010). Distinct MSN firing patterns were associated with either the cue or LP. Figure $1 B$ (left, aligned to cue; right, aligned to LP) shows representative rasters and perievent histograms corresponding to the voltammetry data in the top panels. This representative cell was determined to be cue responsive because the firing rate increased significantly after cue onset.

Of 83 cells, 30\% increased firing rate around LP (Fig. 2B), 13\% increased firing after cue presentation (Fig. 2C), and $37 \%$ de- 

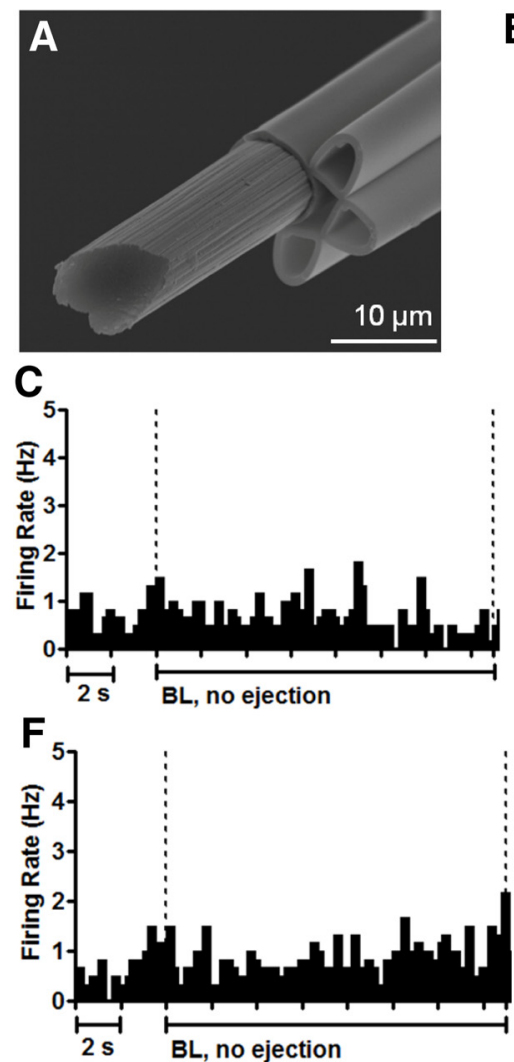

B
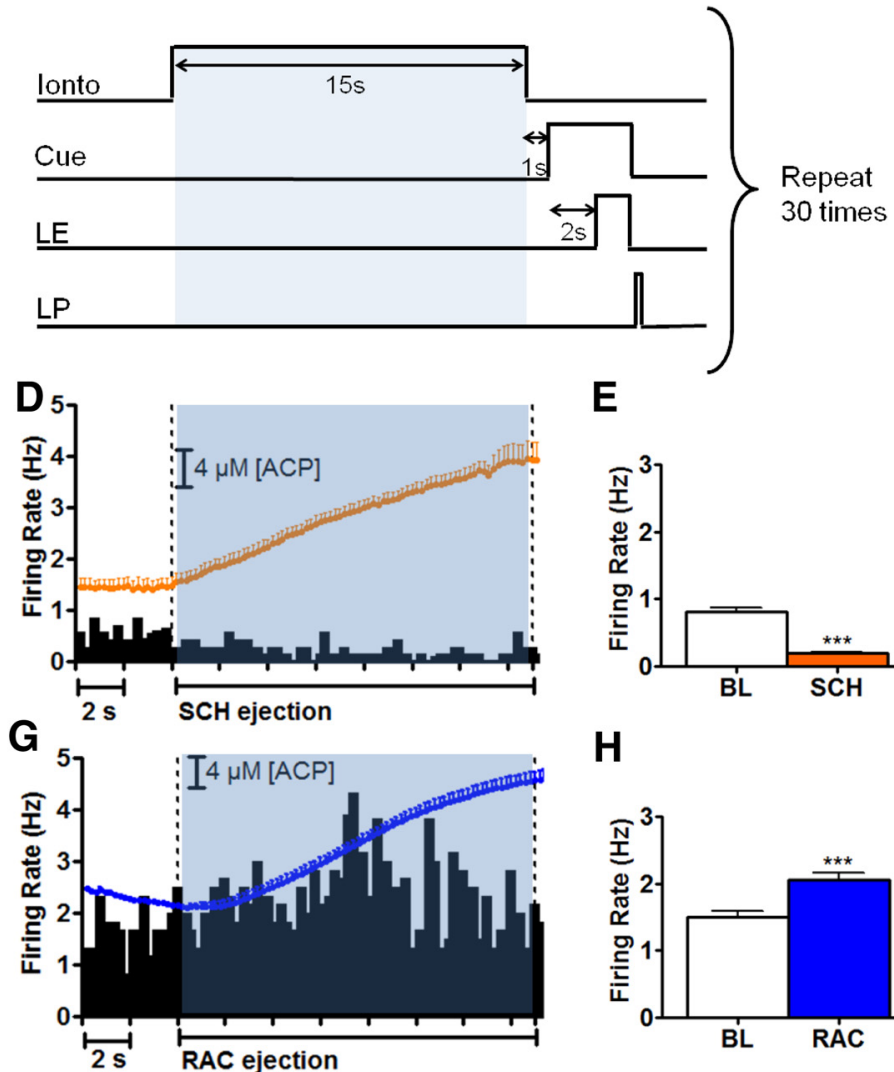

E

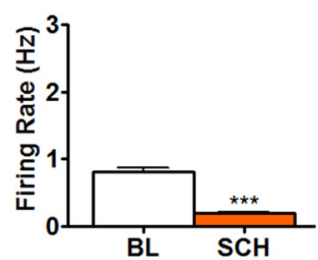

H

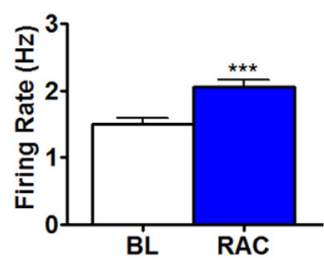

Figure 3. Multimodal sensor and controlled iontophoresis. A, Electron micrograph of a multimodal sensor with three iontophoretic barrels and carbon-fiber electrode. $\boldsymbol{B}$, Timing diagram of the iontophoresis injection period and subsequent ICSS behavioral paradigm. Each trial $(n=30)$ consists of a 15 s ejection period (BL if no drugs were ejected, denoted by the blue shaded region) that ends $1 \mathrm{~s}$ before cue onset. The lever is extended (LE) $2 \mathrm{~s}$ after cue onset and remains available for $15 \mathrm{~s}$ or until the rat presses the lever, whichever occurs first. C, Histogram showing single-unit activity of a representative cell before iontophoretic drug ejection (averaged over 30 trials). Vertical dashed lines indicate beginning and ending of the BL collection period. $\boldsymbol{D}$, Single-unit activity of the same cell during iontophoretic ejection of $S \mathrm{CH}$ (with ACP) at the same location (averaged over 30 ejections). The orange line shows the average local $\mathrm{ACP}$ concentration during the 30 ejections. $E$, Average firing rates of the $\mathrm{D} 1$ cell shown in $\boldsymbol{C}$ and $\boldsymbol{D}$ during the period (indicated by dashed lines) before (BL) and during ejections ( $\left.{ }^{* * *} p<0.001\right)$. $\boldsymbol{F}$, Single-unit activity of another representative cell before iontophoretic drug ejection (averaged over 30 trials). $\mathbf{G}$, Single-unit activity of the same cell shown in $\boldsymbol{F}$ during iontophoretic ejection of RAC (with ACP) at the same location (averaged over 30 ejections). Ejected drug concentration monitored by ACP current (blue line, average of 30 ejections). $\boldsymbol{H}$, Average firing rates for the D2 cell shown in $\boldsymbol{F}$ and $\boldsymbol{G}$ during the period (indicated by dashed lines) before (BL) and during ejections. ${ }^{* * *} p<0.001$.

creased firing before LP and subsequently returned to baseline after LP (Fig. 2D). Changes in dopamine were measured at all locations where phasic cells were recorded (indicated by green in Fig. $2 B, C, D)$. No cells responded to both the cue and LP. The changes in firing rate after the cue were broad, like the dopamine changes, whereas changes around LP were shorter in duration than the changes in dopamine. In agreement with previous findings during ICSS (Cheer et al., 2007), sucrose reward (Cacciapaglia et al., 2011), and cocaine self-administration (OwessonWhite et al., 2009), 20\% of MSNs were NP during task events. Dopamine release was not detected in these locations. Therefore, we found that dopamine transients are associated with specific changes in MSN firing rate during behavior.

Changes in cell firing linked to behavioral events were similar between the two NAc subregions (Fig. $2 B-D$ ). Specifically, cueresponsive cells did not show significant differences in firing rates between the two subregions (Fig. 2B). A two-way ANOVA showed a main effect of time $\left(F_{(9,330)}=3.759, p<0.001\right)$, but no main effect of subregion $\left(F_{(1,330)}=1.291, p>0.05\right)$ and no significant interaction between time and subregion $\left(F_{(9,330)}=\right.$ $0.4717, p>0.05)$. Likewise, firing rates of LP-excitatory cells did not differ significantly between core and shell (Fig. 2C). A twoway ANOVA showed a main effect of time $\left(F_{(9,230)}=2.869, p<\right.$ $0.001)$, but no main effect of subregion $\left(F_{(1,230)}=1.877, p>\right.$
$0.05)$ and no significant interaction between time and subregion $\left(F_{(9,230)}=0.9728, p>0.05\right)$. Finally, LP-inhibitory cells in the core were compared with the LP-inhibitory cells in the shell and the firing rates were not significantly different (Fig. 2D); a twoway ANOVA showed a main effect of time $\left(F_{(9,290)}=2.336, p<\right.$ $0.05)$, but no main effect of subregion $\left(F_{(1,290)}=3.600, p>0.05\right)$, and no significant interaction between time and subregion $\left(F_{(9,290)}=0.115, p>0.05\right)$. Therefore, in subsequent analyses, we combined core and shell measurements.

To examine the relative time response of the dopamine and single-unit firing, we replotted the data in Figure $2, B-D$, without errors and normalized it to cover the maximum observed response (Fig. $2 E-G$ ). For cue-responsive cells, the increase in dopamine occurs as the firing rate increases. For both types of LP-responsive cells, the firing rate change (increase for LP-excitatory and decrease for LP-inhibitory) is maximal before the electrically evoked dopamine reaches its maximum. Indeed, we did not find any firing rate change that followed the electrically stimulated release.

\section{Controlled iontophoresis identifies MSNs by pharmacologic response}

To investigate how dopamine modulates single-unit activity through its different receptors, we used controlled iontophoresis in a different set of animals performing ICSS ( $N=20$ rats). 
A

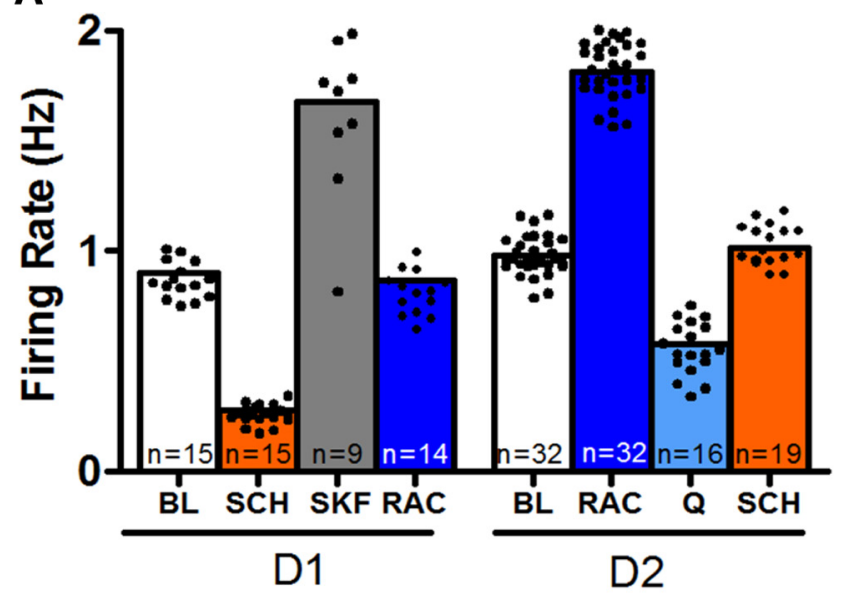

B

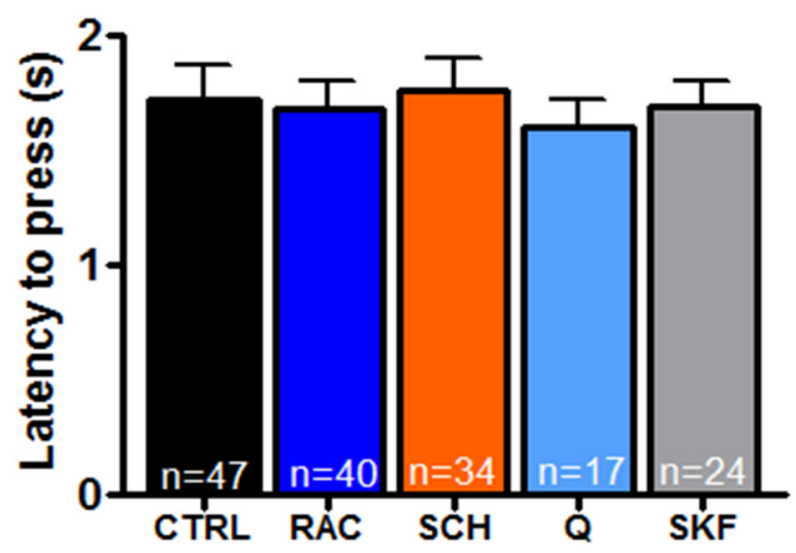

Figure 4. Receptor identification via the multimodal sensor. $A$, Average firing rates recorded during $15 \mathrm{~s}$ periods before $(\mathrm{BL})$ or during iontophoretic ejection of $\mathrm{SCH}$ or RAC during the ITI for all cells. Cell firing changes during iontophoresis relative to BL were used to determine D1R or D2R chemotype. Cell-firing changes to the agonists $Q$ and SKF were used to verify the sorting into D1-responsive MSNs $(n=15)$ and D2-responsive MSNs ( $n=32 s) . N$ in the column refers to how many locations in which each drug was tested; the barrels contained the two antagonist (SCH and RAC) and one agonist (either SKF or Q). Dots show the individual responses to each drug. $\boldsymbol{B}$, Latency to $L P$ after lever extension in the presence of iontophoresed drugs (CTRL without iontophoresed drug, $n=47 ; \mathrm{RAC}, n=40 ; \mathrm{SCH}, n=34 ; \mathrm{Q}, n=17 ; \mathrm{SKF}, n=24$ ).

Figure $3 A$ shows the construction of the controlled iontophoresis probe, which couples three iontophoretic glass barrels to a carbon-fiber microelectrode. Iontophoretic ejections occurred for $15 \mathrm{~s}$ during the ITI of the ICSS task and were evaluated over 30 consecutive trials in each location (Fig. $3 B$ ). This was followed by the cue and lever extension for ICSS. Before iontophoretic delivery, BL firing rates were determined in the same $15 \mathrm{~s}$ period that terminates $1 \mathrm{~s}$ before cue onset (Fig. 3B). To probe D1Rs, we delivered SCH-23390 (SCH; D1R antagonist) or SKF-38393 (SKF; D1R partial agonist); to probe D2Rs, we delivered raclopride (RAC; D2R antagonist) or quinpirole (Q; D2R agonist). BL firing rates were averaged over 30 ICSS trials and used to compare firing rate changes during the $15 \mathrm{~s}$ (30 trials) of subsequent iontophoretic deliveries.

Firing rate changes in response to the antagonists were compared with BL and used to chemotype D1R and D2R responses pharmacologically on adjacent MSNs independently of task events (Belle et al., 2013). Figure 3, C, D, F, and G, shows responses at two different cells to illustrate the time course of drug delivery and the firing rate changes that ensued. For the cell in
Figure 3, $C-E$, ejection of SCH decreased firing rate (Fig. 3D) relative to $\mathrm{BL}$ (Fig. $3 C$ ), as quantified in Figure $3 E$ (average of 30 trials; $t_{(74)}=11.46,{ }^{* *} p<0.0001$, paired two-tailed $t$ test). We classified cells with this type of response as D1R-containing MSNs. In contrast, ejection of RAC increased the firing of the cell in Figure 3, $F-H$, compared with BL (average of 30 trials, Fig. $3 H$, $t_{(149)}=8.904,{ }^{* *} p<0.0001$, paired two-tailed $t$ test). Cells with this type of response were classified as D2R-containing MSNs.

Overall, $96 \%$ of MSNs responded to only one receptor antagonist, consistent with the known distribution of D1Rs and D2Rs (Valjent et al., 2009) and our previous findings (Belle et al., 2013). The firing rates during the $15 \mathrm{~s}$ ejection periods for dopamine agonists and antagonists ( 30 trials) were compared with BL firing rates (30 trials) for all cells (Fig. 4A). Cells classified as D1Rcontaining showed a decrease with $\mathrm{SCH}$, an increase with SKF, and no change with RAC. Cells classified as D2R-containing increased cell firing significantly in response to RAC, decreased firing during Q ejections, and showed no effect of SCH. Overall, the identity of neurons explained the effect of iontophoresed drugs on neuronal firing. A two-way ANOVA across all cells revealed a main effect of cell type $\left(F_{(1,12,215)}=23.7, p<0.0001\right)$ a main effect of ejected drugs $\left(F_{(4,12,215)}=53.6,{ }^{* *} p<0.0001\right)$, and a significant interaction between cell types and ejected drugs $\left(F_{(4,12,215)}=42.8,{ }^{* *} p<0.0001\right)$. Bonferroni's post test revealed significant changes compared with respective baselines $\left({ }^{* * *} p<\right.$ $0.001)$. The firing rate changes that we observed are consistent with the excitatory effect of D1Rs and the inhibitory effect of D2Rs (Tritsch and Sabatini, 2012; Wang et al., 2012).

Roles of specific dopamine receptors during ICSS

Next, we analyzed the recordings made during the ICSS behavior to determine how the firing rate of D1R- and D2R-identified MSNs responded to discrete behavioral events. This was possible because ejected drugs remain at effective concentrations for at least $10 \mathrm{~s}$ after each ejection (Kirkpatrick et al., 2014), so the effects of D1 and D2 agonists and antagonists persisted throughout cue delivery ( $1 \mathrm{~s}$ after termination of iontophoretic delivery) and subsequent ICSS events. In all cases, iontophoretically introduced drugs did not affect the latency to press (one-way repeatedmeasures ANOVA, $F_{(4,116)}=1.401, p>0.05$; Fig. $\left.4 B\right)$. This confirms that the effects of the delivered substances are localized to the neuronal environment at the electrode tip. The majority of cells that changed firing rate proximal to LP were D1R-containing; most were excited $(n=10)$, whereas a few were inhibited $(n=5)$. Another population of MSNs that were chemotyped as D2Rs were LP responsive $(n=9)$, with all but one inhibited. Remarkably, however, every MSN that was cue responsive during ICSS was classified as D2R containing $(n=23)$.

Delivery of D2-selective drugs attenuated $(\mathrm{Q})$ and enhanced (RAC) firing rate in every cue-responsive cell. Figure $5 A$ shows the activity of a single cue-responsive cell, and averaged results from all cue-responsive cells are shown in Figure 5B. Control (CTRL) refers to periods without iontophoresed drug. Firing rates to the different drug deliveries during the task baseline period (left) and for the same cue-responsive cells (right) are summarized in Figure 5C. RAC significantly increased firing during the task baseline period and after the cue relative to the control period. For these same cells, Q did not affect firing during task baseline, but significantly attenuated activity after the cue (twoway ANOVA identified a main effect of ejected drugs, $F_{(4,1052)}=$ $57.75,{ }^{* * *} p<0.001$, a main effect of time, $F_{(1,1052)}=127.9$, ${ }^{* * *} p<0.001$, and a significant interaction between ejected drugs and time, $\left.F_{(4,1052)}=9.113,{ }^{* *} p<0.001\right)$. Bonferroni's test 
A Cue-responsive

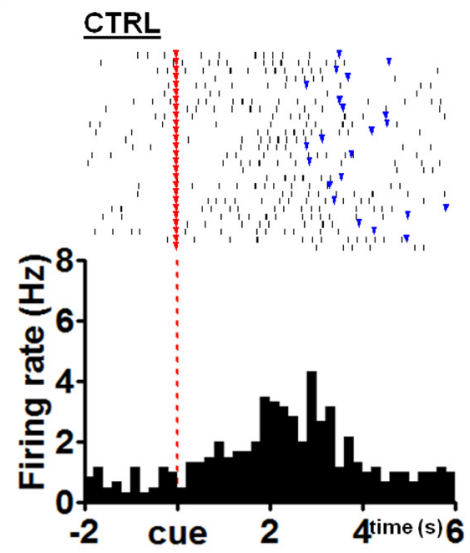

$\underline{Q}$

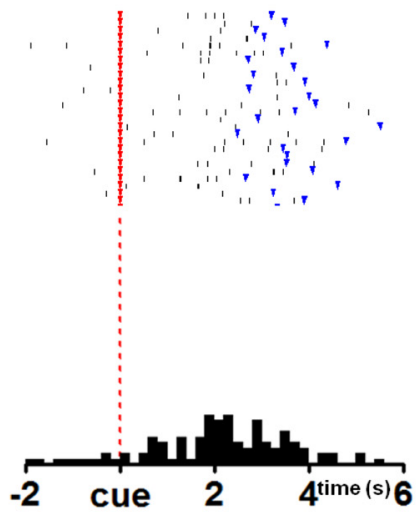

$\underline{\mathrm{RAC}}$

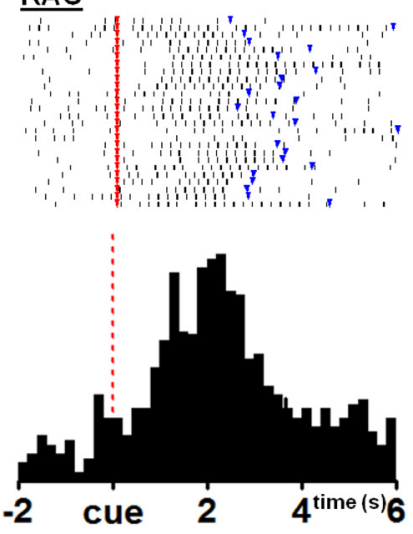

B

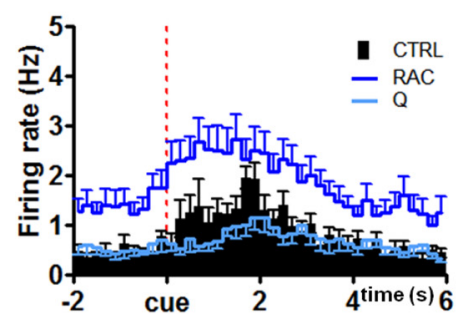

C

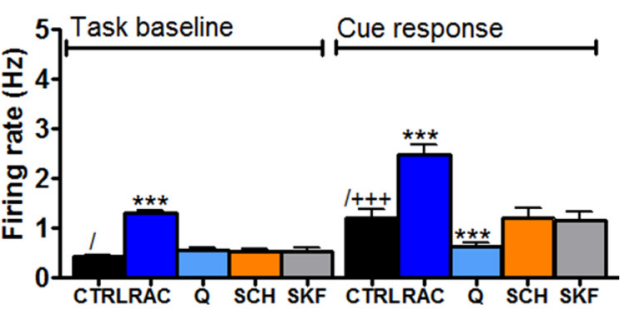

D

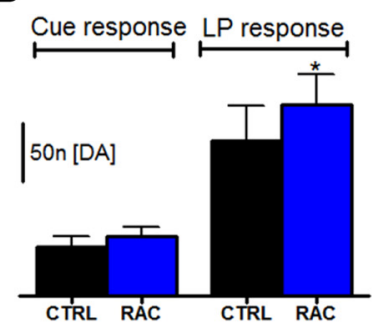

Figure 5. D2-mediated responses after the cue. $A$, Raster plots and histograms of firing rate from a single cue-responsive MSN during the ICSS task. Traces are aligned to cue onset (time 0 ). CTRL, Without iontophoresed drug; $Q$, in the presence of iontophoresed $Q ;$ RAC, in the presence of iontophoresed RAC. $B$, Summary histogram of all D2R cue-responsive cells ( $n=23$ ). $C$, Drug effects on task baseline and cue response firing on D2 cue cells. ${ }^{* *} p<0.001$ for task baseline RAC compared task baseline CTRL and $/+++p<0.001$ cue response CTRL compared with/task CTRL. $D$, Effects on cue-evoked and electrically evoked dopamine release after LP during ICSS (cue, ns; LP response, ${ }^{*} p<0.05$ ).

showed that RAC increased the cell-firing rate significantly during both task baseline and cue response $\left({ }^{* * *} p<0.001\right)$ and that $\mathrm{Q}$ decreased the cell-firing rate significantly during cue response $\left.{ }^{* * *} p<0.001\right)$ compared with CTRL. Further, CTRL firing rates during task baseline $(/)$ were significantly lower than CTRL cue response $(/+++p<0.001)$, whereas D1-selective drugs had no effect on these cells. Note that the endogenous dopamine release does not cause the excitation, but rather suppresses the excitatory inputs to a population of D2-containing MSNs.

In addition to postsynaptic effects, D2Rs can function as presynaptic autoreceptors that inhibit dopamine release (Ford, 2014). Therefore, it is possible that iontophoresing a D2 antagonist (RAC) alters MSN firing by increasing presynaptic dopamine release, rather than through postsynaptic effects. To determine whether iontophoresis of antagonists had presynaptic effects, we examined how dopamine released at the cue and LP was affected after ejections of these drugs. RAC increased the electrically evoked dopamine release slightly after LP, whereas release at the cue was unaffected (Fig. $5 D$; LP response: $t_{(13)}=2.2{ }^{\star} p<0.05$, cue: $t_{(13)}=0.963, p>0.05$; paired two-tailed $t$ test). SCH had no effect on the amplitude of dopamine release. Therefore, the modulatory effects of autoreceptors on dopamine release are less significant than the D2 modulation of unit activity during ICSS.

D1 cells excited around LP tended to be suppressed by SCH but unaffected by SKF and the D2 drugs (a single cell is shown in Fig. $6 \mathrm{~A}$ and the average across all cells is shown in Fig. 6B). Cellfiring changes during task baseline and LP responses for all excitatory D1 cells showed that $\mathrm{SCH}$ attenuated cell firing significantly during both task baseline and LP response (two-way ANOVA identified a main effect of ejected drugs (Fig. $6 C, F_{(3,505)}=8.732$, $\left.{ }^{* * *} p<0.001\right)$, with a main effect on time $\left(F_{(1,505)}=12.99,{ }^{* *} p<\right.$
$0.001)$ and a significant interaction between ejected drugs and time $\left(F_{(3,505)}=2.872,{ }^{\star} p<0.05\right)$. Bonferroni's post test revealed that $\mathrm{SCH}$ significantly decreased cell-firing rates compared with respective controls during both task baseline and LP response $\left({ }^{* * *} p<0.001\right)$. Further, CTRL during task baseline $(/)$ was significantly lower than CTRL task response $(/+++p<001)$. At these cells, dopamine enhances the excitatory responses driven by inputs to the MSNs. Our failure to observe a significant effect of SKF may indicate a short-lived effect of this partial agonist because it was effective during its delivery for identifying D1 cells.

A third group of cells were inhibited at the time of the LP (Fig. $7 A, B)$ and contained either D1Rs or D2Rs. D2-inhibitory cells decreased cell firing significantly around the LP; two-way ANOVA showed a main effect of drugs $\left(F_{(2,265)}=7.83, p<\right.$ $0.001)$, a main effect of time $\left(F_{(1,265)}=4.42, p<0.05\right)$, and no significant interaction between ejected drugs and time $\left(F_{(2,266)}=\right.$ $0.7166, p>0.05)$. D1-inhibitory cells decreased cell firing significantly around the LP (two-way ANOVA identified a main effect of ejected drugs $\left(F_{(3,428)}=5.510, p<0.01\right)$, a main effect on time $\left(F_{(1,428)}=6.758, p<0.01\right)$, and no interaction between drug and time $\left(F_{(3,428)}=2.335, p<0.05\right)$. The frequency at which these MSNs were identified was insufficient for more complete characterization. We speculate that this group may arise from indirect activation via interneurons or collateral innervation.

\section{Discussion}

Although it is well established that dopamine in the NAc plays an important role in reward-based behaviors, the mediation of its effects at the receptor level has remained elusive. The NAc is organized into discrete microcircuits based on anatomical and physiological features (Pennartz et al., 1994; Carelli and Wight- 
A LP-excitatory CTRL

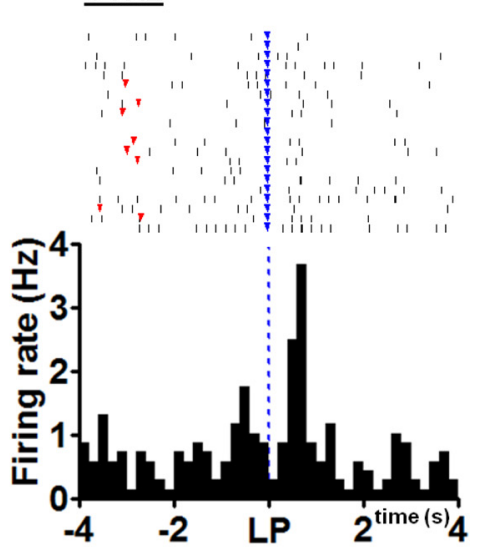

B

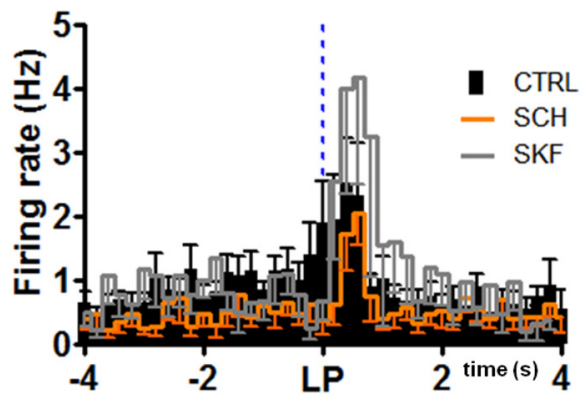

$\underline{\text { SKF }}$

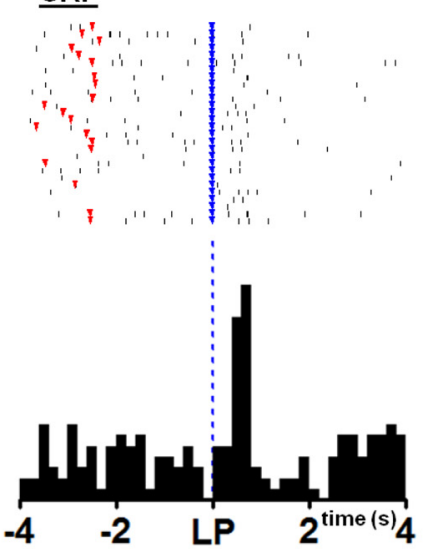

C
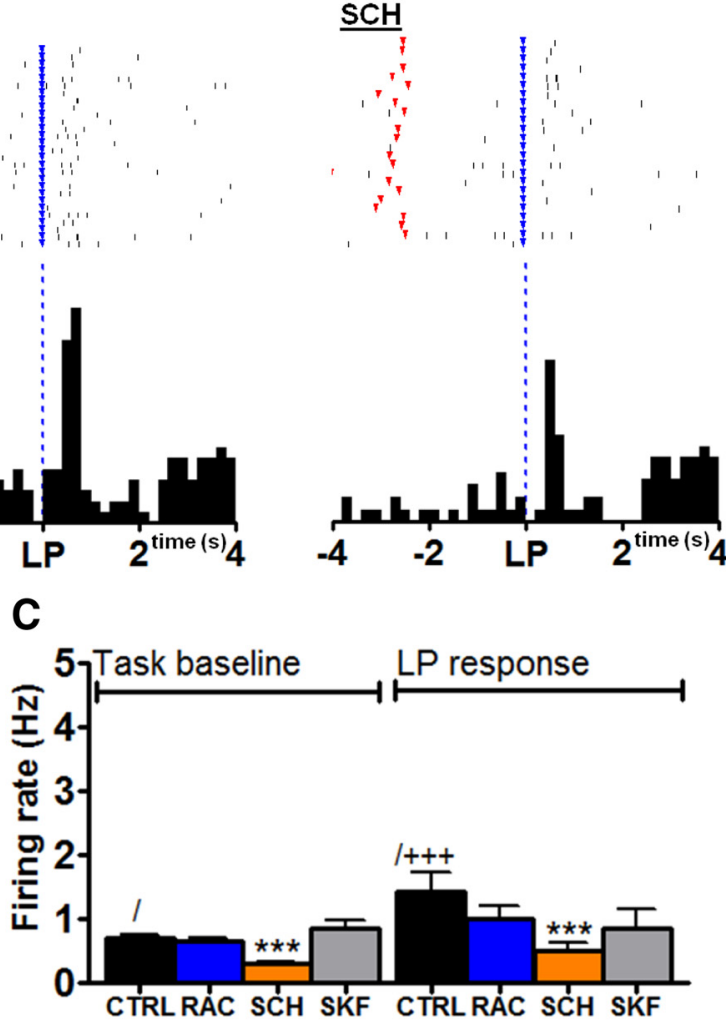

Figure 6. Excitatory D1 responses around LP.A, Example histograms and raster plots showing firing rates from a single LP-excitatory MSN. CTRL, Without added drug; SKF, in the presence of SKF; $S C H$, in the presence of SCH. $B$, Summary histogram of all D1R LP-excitatory cells $(n=10)$. C, Drug effects on baseline and task response firing on D1-like LP-excitatory cells. *** $p<0.001$ for task baseline SCH compared with task baseline CTRL and $/+++p<0.001$ LP response CTRL compared with/task CTRL.

man, 2004). Here, we show that this organization is defined by differential expression of dopamine receptors on MSNs. Our experiments reveal that dopamine-mediated responses after the cue activate a subset of D2R-expressing MSNs exclusively, whereas both dopamine receptor types modulate the responses of MSNs that respond around LP. Consistent with our findings, rats that react to signs (cues) rather than goals have a greater proportion of dopamine D2 high-affinity state receptors in the ventral striatum (Flagel et al., 2010). Therefore, our findings are consistent with prior reports demonstrating the importance of D2Rs in mediating information concerning responses to reward-associated cues.

We used controlled iontophoresis for chemotyping the dopaminergic receptor type on specific MSNs (Belle et al., 2013). Although iontophoresis has been used previously in freely moving animals (Kiyatkin and Rebec, 1999; Wang et al., 2004), findings with this approach have varied between studies. The relatively straightforward results in this study are in part due to key aspects of our experimental design. First, the voltammetric electrode enables subsecond detection of dopamine, as well as the ability to monitor the concentration of iontophoretically introduced drugs. Second, the segregation of D1Rs and D2Rs at most MSNs simplified analysis (Valjent et al., 2009). Third, the presence of dopamine tone in the awake animal enabled the use of doses of selective agonists and antagonists that caused only a modest alteration of the natural firing rate of MSNs. The suppression of D2R-containing MSN firing by increased dopamine tone, and the opposite result at D1R-containaing MSNs, is identical to that found in mice genetically altered to allow monitoring of MSN $\mathrm{Ca}^{2+}$ activity (Calipari et al., 2016).
The output of the dorsal striatum of the basal ganglia can be divided into two distinct projection pathways: the direct (D1mediated) and indirect (D2-mediated) pathways. The anatomical arrangement of the NAc, however, is not completely analogous. Kupchik et al. (2015) described one pathway from the NAc core that leads directly to the midbrain and contains only D1-containing MSNs. However, the NAc core projection to the ventral pallidum is a mixture of both D1- and D2-containing MSNs. Importantly, in this study, only a subset of MSNs in the latter pathway were activated by reward-related cues and these were the ones dampened by dopamine release through interaction with D2Rs.

MSNs were found to respond in distinct patterns during ICSS, depending on the dopamine receptor type that they contained. Our prior work demonstrated that cue-evoked dopamine release is a learned association of pending lever availability (OwessonWhite et al., 2008) that is triggered by glutamatergic receptors in the VTA (Sombers et al., 2009). Here, we demonstrate that this cue-evoked dopamine initially activates a subset of D2Rs on MSNs. Approximately $1.5 \mathrm{~s}$ after cue presentation, in anticipation of lever availability, parallel cortical and subcortical circuits activate a separate population of MSNs. The predominant type of MSNs are D1-containing and increase their firing rate (the inhibitions that occurred at this time were too few to characterize completely).

These findings, and the proposed neural pathways underlying the sequence of events during ICSS, are summarized schematically in Figure 8. The initially responsive cells, the ones we term "cue responsive," were found to be D2R containing. Activation of 


\section{A D2 Inhibitory cells}
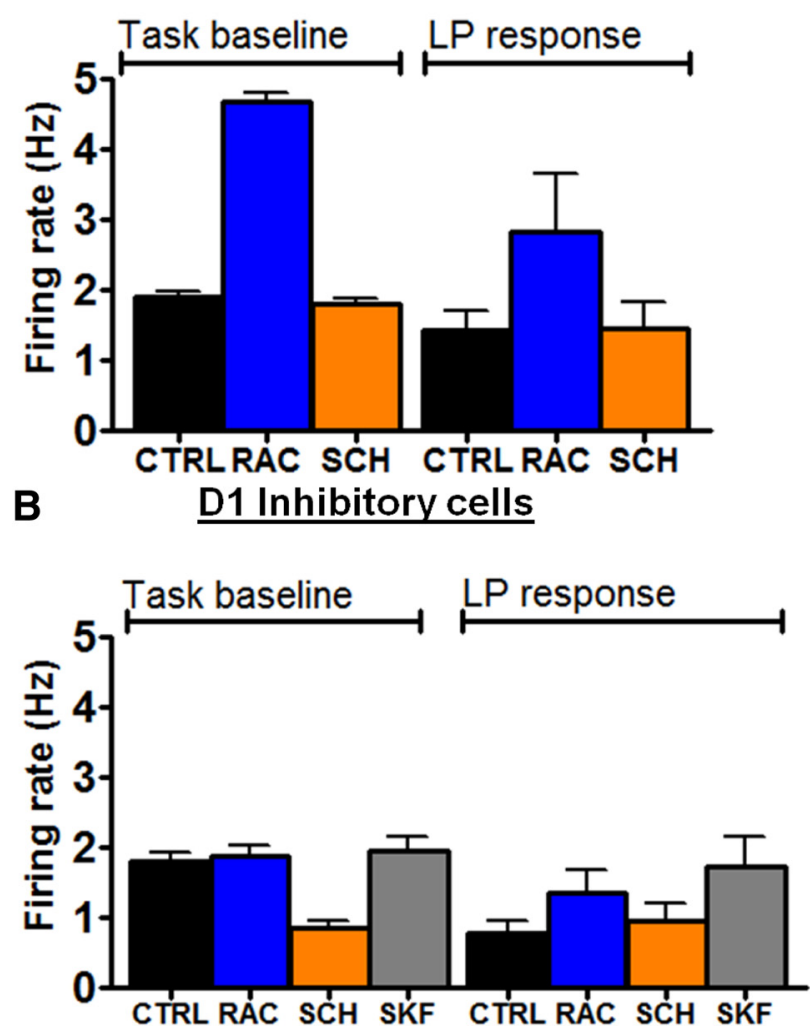

C

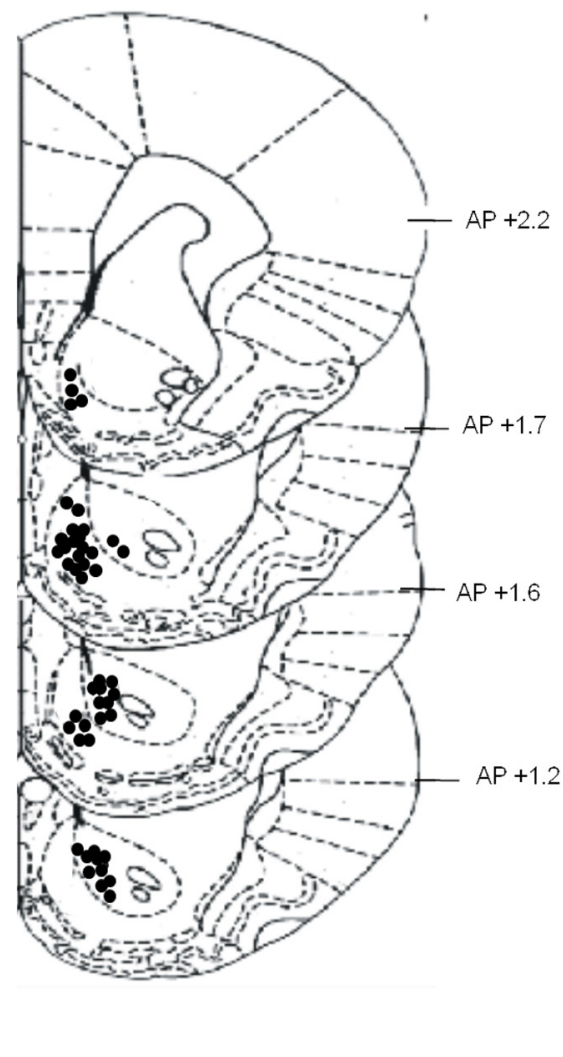

Figure 7. Inhibitory LP responses and recording sites. $\boldsymbol{A}$, Reinforced inhibitory cells at $L P$ that responded to D2 drugs $\left.{ }^{* * *} p<0.001\right) . B$, Reinforced inhibitory cells that responded to D1 drugs $\left({ }^{* *} p<0.01\right) . C$, Coronal sections ranging from 1.2 to 2.2 anterior to bregma, adapted from Paxinos and Watson (2007). Approximate recording sites are displayed by black circles; for clarity and due to overlapping sites, all sites are not shown.

D2R-containing MSNs has been shown to be aversive (Kravitz et al., 2012), an effect that can be suppressed by activation of the D2Rs (Wang et al., 2012). Consistent with these results, dopamine inhibits excitatory actions at these MSNs in our study. Therefore, our results demonstrate, for the first time during behavior, that this D2-mediated suppression is a consequence of dopamine release triggered by the cue. The synaptic architecture at MSNs containing D2Rs allows dopaminergic modulation of cannabinoids and adenosine that promote high-pass filtering of glutamatergic afferents (André et al., 2010; Wang et al., 2012; Wong et al., 2015). Indeed, activation of D2Rs on MSNs has been suggested to promote switching from ongoing behavior to lever approach (van den Bos et al., 1991; Nicola, 2010). In this case, suppression of the "aversive" effects of excitation of the D2containing MSNs allows the behavior to switch to awaiting the lever.

The second event diagrammed in Figure 8 is the action of dopamine at D1Rs on a different population of MSNs that enhances their subsequent excitatory responses. Because this occurs proximal to the cue, but before dopamine release is evoked by the electrical stimulation, it is also mediated by the cue-evoked dopamine release. Prolonged modulation can occur because dopamine-receptor interactions are delayed by volume transmission involving release sites remote from their targets (Cragg and Rice, 2004). Additional delays, up to 100 s of milliseconds, are due to the effects of receptor binding being transduced through second messenger cascades (Greengard, 2001; Marcott et al., 2014). Optogenetic activation of MSNs containing D1Rs is reinforcing (Kravitz et al., 2012) and, in brain slices, activation of D1Rs on
NAc MSNs promotes excitation (Wang et al., 2012). Therefore, the net effect in our study is a dopamine-modulated increase in the excitation of this reinforcing direct pathway.

Concurrent measurement of dopamine release and unit activity allowed dopamine autoreceptor function to be monitored alongside receptor-mediated changes in unit activity. Although the D2 antagonist raclopride revealed that autoreceptors were activated, this was only significant for release events after LP. Therefore, autoreceptor effects were small relative to the D2evoked changes in unit activity.

Our method to evaluate a region's function is complemented by others that examined an alteration in behavioral output. For example, recent advances in understanding brain circuitry associated with reward have used optogenetic approaches (Stuber et al., 2011; Kravitz et al., 2012; Cui et al., 2013; Steinberg et al., 2013; Calipari et al., 2016) to link neuronal circuit output to specific behaviors. Our method uses controlled iontophoresis to manipulate a restricted local area pharmacologically to characterize receptor-mediated responses without disrupting behavior. This feature enabled the unraveling of the complex pathways that are involved in reward processing in the ventral striatum. Although it is a highly effective approach, optogenetics could not have dissected the two populations of D2-containing cells (cueresponsive and LP-inhibitory) that were revealed in the present study. Although our approach can distinguish the D1 and D2 classification of dopamine receptors, existing pharmacology is not sufficiently selective to distinguish between their subtypes (e.g., D2Rs and D3Rs). However, in the NAc core, the predominant dopamine receptor subtypes are D1Rs and D2Rs (Gan- 


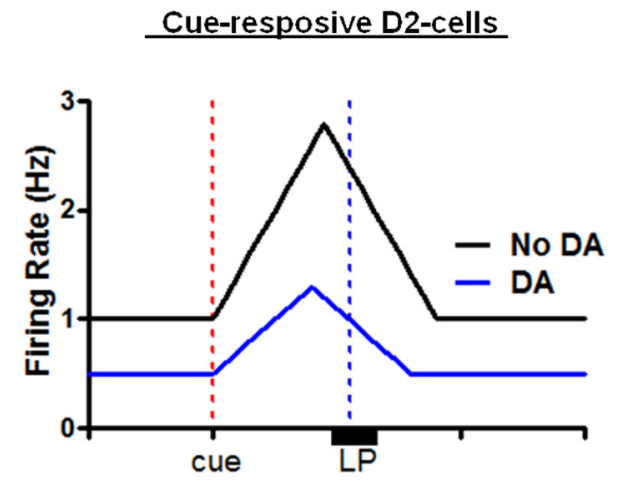

D2-portion of the Indirect Pathway

\section{LP-excitatory D1-cells}

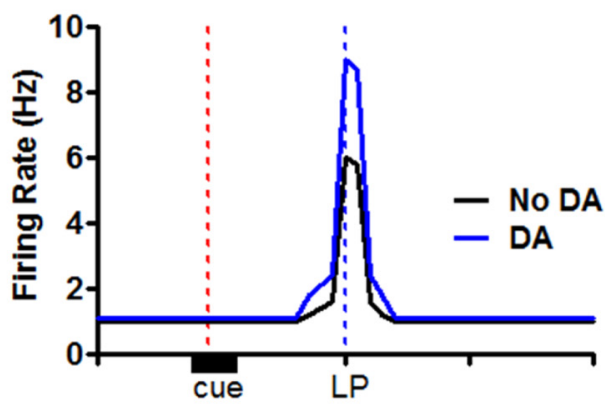

Direct Pathway

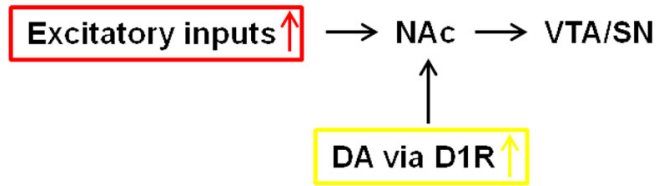

Figure 8. Overview of temporal sequence of MSN cell-firing patterns and neural pathways activated during the ICSS task. Shown is a schematic diagram of the major cell-firing patterns and relationship to MSNs containing specific dopamine receptors during the ICSS behavioral sequence. After the cue, excitatory input activates D2-containing MSNs. Dopamine release in response to the cue suppresses this activation via D2Rs. The net result is that the inhibitory projection to the ventral pallidum (VP) described by Kupchik et al. (2015) is suppressed. Shortly before the rat presses the lever for the electrical stimulation, a separate population of MSNs that contains D1Rs is excited. Dopamine release triggered by the cue is still present and promotes this excitation. The net result of this is that the inhibitory actions of the MSNs that project to the VTA (Kupchik et al., 2015) are enhanced.

garossa et al., 2013). Because indistinguishable responses were obtained in the NAc shell after the training period, we assume that the same processes are operating there despite its significant D3R expression.

In summary, our findings provide a link between dopamine release and cue responsivity that establishes clearly that it is the exclusive domain of D2Rs in the NAc. Given our previous findings that cue-evoked dopamine extinguishes rapidly during extinction (Owesson-White et al., 2008), the link between D2R activation and the cue may be causal. Furthermore, this finding likely extends to other reward-based behaviors because similar changes in extracellular dopamine and firing rate occur in the NAc during a behavioral paradigm in which a cue signals the impending lever availability for food (Cacciapaglia et al., 2011). Understanding the specific circuits associated with dopamine's regulation of reward-mediated behaviors is necessary to determine the mechanisms that influence reward learning, which becomes hijacked by drugs of abuse (Koob and Volkow, 2010; Bock et al., 2013). This work establishes that the responses in the NAc are quite different from those measured previously in the dorsal striatum, where studies using optogenetic monitoring of dopamine neurons have shown that D1Rs and D2Rs work simultaneously (Cui et al., 2013). In contrast, in the present study, a subpopulation of NAc D2Rs was activated at the cue, whereas D1Rs were activated later, near the time of the LP. This work provides a unique insight into the role of the $\mathrm{D} 2 \mathrm{R}$-mediated neuronal activity in the ventral striatum during cue-evoked responses that have been suggested to support motivation both in genetically altered mice (Trifilieff et al., 2013) and humans (Volkow et al., 2011).

\section{References}

André VM, Cepeda C, Cummings DM, Jocoy EL, Fisher YE, William Yang X, Levine MS (2010) Dopamine modulation of excitatory currents in the striatum is dictated by the expression of D1 or D2 receptors and modified by endocannabinoids. Eur J Neurosci 31:14-28. CrossRef Medline

Belle AM, Owesson-White C, Herr NR, Carelli RM, Wightman RM (2013) Controlled iontophoresis coupled with fast-scan cyclic voltammetry/electrophysiology in awake, freely moving animals. ACS Chem Neurosci 4:761-771. CrossRef Medline

Bock R, Shin JH, Kaplan AR, Dobi A, Markey E, Kramer PF, Gremel CM, Christensen CH, Adrover MF, Alvarez VA (2013) Strengthening the accumbal indirect pathway promotes resilience to compulsive cocaine use. Nat Neurosci 16:632-638. CrossRef Medline

Britt JP, Benaliouad F, McDevitt RA, Stuber GD, Wise RA, Bonci A (2012) Synaptic and behavioral profile of multiple glutamatergic inputs to the nucleus accumbens. Neuron 76:790-803. CrossRef Medline

Bucher ES, Brooks K, Verber MD, Keithley RB, Owesson-White C, Carroll S, Takmakov P, McKinney CJ, Wightman RM (2013) Flexible software platform for fast-scan cyclic voltammetry data acquisition and analysis. Anal Chem 85:10344-10353. CrossRef Medline

Cacciapaglia F, Wightman RM, Carelli RM (2011) Rapid dopamine signaling differentially modulates distinct microcircuits within the nucleus ac- 
cumbens during sucrose-directed behavior. J Neurosci 31:13860-13869. CrossRef Medline

Calipari ES, Bagot RC, Purushothaman I, Davidson TJ, Yorgason JT, Pena CJ, Walker DM, Pirpinias ST, Guise KG, Ramakrishnan C, Deisseroth K, Nestler EJ (2016) In vivo imaging identifies temporal signature of $\mathrm{D} 1$ and $\mathrm{D} 2$ medium spiny neurons in cocaine reward. Proc Natl Acad Sci U S A.

Carelli RM, Wightman RM (2004) Functional microcircuitry in the accumbens underlying drug addiction: insights from real-time signaling during behavior. Curr Opin Neurobiol 14:763-768. CrossRef Medline

Cheer JF, Heien ML, Garris PA, Carelli RM, Wightman RM (2005) Simultaneous dopamine and single-unit recordings reveal accumbens GABAergic responses: implications for intracranial self-stimulation. Proc Natl Acad Sci U S A 102:19150-19155. CrossRef Medline

Cheer JF, Aragona BJ, Heien ML, Seipel AT, Carelli RM, Wightman RM (2007) Coordinated accumbal dopamine release and neural activity drive goal-directed behavior. Neuron 54:237-244. CrossRef Medline

Cragg SJ, Rice ME (2004) DAncing past the DAT at a DA synapse. Trends Neurosci 27:270-277. CrossRef Medline

Cui G, Jun SB, Jin X, Pham MD, Vogel SS, Lovinger DM, Costa RM (2013) Concurrent activation of striatal direct and indirect pathways during action initiation. Nature 494:238-242. CrossRef Medline

du Hoffmann J, Nicola SM (2014) Dopamine invigorates reward seeking by promoting cue-evoked excitation in the nucleus accumbens. J Neurosci 34:14349-14364. CrossRef Medline

Flagel SB, Robinson TE, Clark JJ, Clinton SM, Watson SJ, Seeman P, Phillips PE, Akil H (2010) An animal model of genetic vulnerability to behavioral disinhibition and responsiveness to reward-related cues: implications for addiction. Neuropsychopharmacology 35:388-400. CrossRef Medline

Ford CP (2014) The role of D2-autoreceptors in regulating dopamine neuron activity and transmission. Neuroscience 282C:13-22. CrossRef Medline

Gage GJ, Stoetzner CR, Wiltschko AB, Berke JD (2010) Selective activation of striatal fast-spiking interneurons during choice execution. Neuron 67: 466-479. CrossRef Medline

Gangarossa G, Espallergues J, de Kerchove d'Exaerde A, El Mestikawy S, Gerfen CR, Hervé D, Girault JA, ValjentE (2013) Distribution and compartmental organization of GABAergic medium-sized spiny neurons in the mouse nucleus accumbens. Front Neural Circuits 7:22. CrossRef Medline

Gerfen CR, Surmeier DJ (2011) Modulation of striatal projection systems by dopamine. Annu Rev Neurosci 34:441-466. CrossRef Medline

Greengard P (2001) The neurobiology of slow synaptic transmission. Science 294:1024-1030. CrossRef Medline

Herr NR, Daniel KB, Belle AM, Carelli RM, Wightman RM (2010) Probing presynaptic regulation of extracellular dopamine with iontophoresis. ACS Chem Neurosci 1:627-638. CrossRef Medline

Ikemoto S (2007) Dopamine reward circuitry: two projection systems from the ventral midbrain to the nucleus accumbens-olfactory tubercle complex. Brain Res Rev 56:27-78. CrossRef Medline

Kirkpatrick DC, Edwards MA, Flowers PA, Wightman RM (2014) Characterization of solute distribution following iontophoresis from a micropipet. Anal Chem 86:9909-9916. CrossRef Medline

Kiyatkin EA, Rebec GV (1999) Striatal neuronal activity and responsiveness to dopamine and glutamate after selective blockade of D1 and d2 dopamine receptors in freely moving rats. J Neurosci 19:3594-3609. Medline

Koob GF, Volkow ND (2010) Neurocircuitry of addiction. Neuropsychopharmacology 35:217-238. CrossRef Medline

Kravitz AV, Tye LD, Kreitzer AC (2012) Distinct roles for direct and indirect pathway striatal neurons in reinforcement. Nat Neurosci 15:816-818. CrossRef Medline

Kupchik YM, Brown RM, Heinsbroek JA, Lobo MK, Schwartz DJ, Kalivas PW (2015) Coding the direct/indirect pathways by D1 and D2 receptors is not valid for accumbens projections. Nat Neurosci 18:1230-1232. CrossRef Medline

Marcott PF, Mamaligas AA, Ford CP (2014) Phasic dopamine release drives rapid activation of striatal d2-receptors. Neuron 84:164-176. CrossRef Medline

Nicola SM (2010) The flexible approach hypothesis: unification of effort and cue-responding hypotheses for the role of nucleus accumbens dopamine in the activation of reward-seeking behavior. J Neurosci 30: 16585-16600. CrossRef Medline

Owesson-White CA, Cheer JF, Beyene M, Carelli RM, Wightman RM (2008) Dynamic changes in accumbens dopamine correlate with learning during intracranial self-stimulation. Proc Natl Acad Sci U S A 105:11957-11962. CrossRef Medline
Owesson-White CA, Ariansen J, Stuber GD, Cleaveland NA, Cheer JF, Wightman RM, Carelli RM (2009) Neural encoding of cocaine-seeking behavior is coincident with phasic dopamine release in the accumbens core and shell. Eur J Neurosci 30:1117-1127. CrossRef Medline

Paxinos G, Watson C (2007) The rat brain in stereotaxic coordinates, Ed 6. Amsterdam: Elsevier.

Pennartz CM, Groenewegen HJ, Lopes da Silva FH (1994) The nucleus accumbens as a complex of functionally distinct neuronal ensembles: an integration of behavioural, electrophysiological and anatomical data. Prog Neurobiol 42:719-761. CrossRef Medline

Phillips PE, Stuber GD, Heien ML, Wightman RM, Carelli RM (2003) Subsecond dopamine release promotes cocaine seeking. Nature 422: 614-618. CrossRef Medline

Rodeberg NT, Johnson JA, Cameron CM, Saddoris MP, Carelli RM, Wightman RM (2015) Construction of training sets for valid calibration of in vivo cyclic voltammetric data by principal component analysis. Anal Chem 87:11484-11491. CrossRef Medline

Schultz W (2007) Multiple dopamine functions at different time courses. Annu Rev Neurosci 30:259-288. CrossRef Medline

Schultz W, Dayan P, Montague PR (1997) A neural substrate of prediction and reward. Science 275:1593-1599. CrossRef Medline

Schultz W, Carelli RM, Wightman RM (2015) Phasic dopamine signals: from subjective reward value to formal economic utility. Curr Opin Behav Sci 5:147-154. CrossRef Medline

Sombers LA, Beyene M, Carelli RM, Wightman RM (2009) Synaptic overflow of dopamine in the nucleus accumbens arises from neuronal activity in the ventral tegmental area. J Neurosci 29:1735-1742. CrossRef Medline

Steinberg EE, Keiflin R, Boivin JR, Witten IB, Deisseroth K, Janak PH (2013) A causal link between prediction errors, dopamine neurons and learning. Nat Neurosci 16:966-973. CrossRef Medline

Steinberg EE, Boivin JR, Saunders BT, Witten IB, Deisseroth K, Janak PH (2014) Positive reinforcement mediated by midbrain dopamine neurons requires D1 and D2 receptor activation in the nucleus accumbens. PLoS One 9:e94771. CrossRef Medline

Stuber GD, Sparta DR, Stamatakis AM, van Leeuwen WA, Hardjoprajitno JE, Cho S, Tye KM, Kempadoo KA, Zhang F, Deisseroth K, Bonci A (2011) Excitatory transmission from the amygdala to nucleus accumbens facilitates reward seeking. Nature 475:377-380. CrossRef Medline

Takmakov P, McKinney CJ, Carelli RM, Wightman RM (2011) Instrumentation for fast-scan cyclic voltammetry combined with electrophysiology for behavioral experiments in freely moving animals. Rev Sci Instrum 82:074302. CrossRef Medline

Trifilieff P, Feng B, Urizar E, Winiger V, Ward RD, Taylor KM, Martinez D, Moore H, Balsam PD, Simpson EH, Javitch JA (2013) Increasing dopamine D2 receptor expression in the adult nucleus accumbens enhances motivation. Mol Psychiatry 18:1025-1033. CrossRef Medline

Tritsch NX, Sabatini BL (2012) Dopaminergic modulation of synaptic transmission in cortex and striatum. Neuron 76:33-50. CrossRef Medline

Valjent E, Bertran-Gonzalez J, Hervé D, Fisone G, Girault JA (2009) Looking BAC at striatal signaling: cell-specific analysis in new transgenic mice. Trends Neurosci 32:538-547. CrossRef Medline

van den Bos R, Charria Ortiz GA, Bergmans AC, Cools AR (1991) Evidence that dopamine in the nucleus accumbens is involved in the ability of rats to switch to cue-directed behaviours. Behav Brain Res 42:107-114. CrossRef Medline

Volkow ND, Wang GJ, Newcorn JH, Kollins SH, Wigal TL, Telang F, Fowler JS, Goldstein RZ, Klein N, Logan J, Wong C, Swanson JM (2011) Motivation deficit in $\mathrm{ADHD}$ is associated with dysfunction of the dopamine reward pathway. Mol Psychiatry 16:1147-1154. CrossRef Medline

Wang M, Vijayraghavan S, Goldman-Rakic PS (2004) Selective D2 receptor actions on the functional circuitry of working memory. Science 303: 853-856. CrossRef Medline

Wang W, Dever D, Lowe J, Storey GP, Bhansali A, Eck EK, Nitulescu I, Weimer J, Bamford NS (2012) Regulation of prefrontal excitatory neurotransmission by dopamine in the nucleus accumbens core. J Physiol 590:3743-3769. CrossRef Medline

Wise RA (2004) Dopamine, learning and motivation. Nat Rev Neurosci 5:483-494. Medline

Wong MY, Borgkvist A, Choi SJ, Mosharov EV, Bamford NS, Sulzer D (2015) Dopamine-dependent corticostriatal synaptic filtering regulates sensorimotor behavior. Neuroscience 290:594-607. CrossRef Medline

Zahm DS, Heimer L (1990) Two transpallidal pathways originating in the rat nucleus accumbens. J Comp Neurol 302:437-446. CrossRef Medline 